\title{
Thermal Analysis and Optimization of 6.4 W Si-Based Multichip LED Packaged Module
}

\author{
Zorigt Chuluunbaatar*, Nam Young Kim
}

\begin{abstract}
Multichip packaging was achieved the best solution to significantly reduce thermal resistance at the same time, to increase luminance intensity in LEDs packaging application. For the packaging, thermal spreading resistance is an important parameter to get influence the total thermal performance of LEDs. In this study, silicon-based multichip light emitting diodes (LEDs) packaged module has been examined for thermal characteristics in several parameters. Compared to the general conventional single LED packaged chip module, multichip LED packaged module has many advantages of low cost, low density, small size, and low thermal resistance. This analyzed module is comprised of multichip LED array, which consists of 32 LED packaged chips with supplement power of $0.2 \mathrm{~W}$ at every single chip. To realize the extent of thermal distribution, the computer-aided design model of 6.4 W Si-based multichip LED module was designed and was performed by the simulation basis of actual fabrication flow. The impact of thermal distribution is analyzed in alternative ways both optimizing numbers of fins and the thickness of that heatsink. In addition, a thermal resistance model was designed and derived from analytical theory. The optimum simulation results satisfies the expectations of the design goal and the measurement of IR camera results. tart after striking space key 2 times.
\end{abstract}

Key Words : Light Emitting Diode, Silicon, Heatsink, Substrate, Thermal Resistance

\section{I . Introduction}

A light emitting diode (LED) is a semiconductor device composed of group II - VI or III - V elements. Depending on their energy gaps, light of color is controlled. LEDs have many advantages of low power consumption, highly directional light emission, fast response time, long lifetime and environmental protection and used in variety of applications such as LCD back light source, automotive and general lighting due to precise wavelength and color output, long lifetime, anti-vibration ${ }^{[1-2]}$. Generally, $17 \%$ of the primary energy consumption in homes is consumed by lighting applications. Therefore, the white LED and its applications could replace the traditional light bulb in the near future ${ }^{[3]}$. When designing an LED lighting system, there is need proper structure to control LED junction temperature. It can improve the capability of heat conduction from the chip to the heat sink by optimizing the internal packaging structure of LED device ${ }^{[4]}$. For example, the lifetime of LEDs decreases from $42,000 \mathrm{~h}$ to $18,000 \mathrm{~h}$, when the junction temperature increases from $40{ }^{\circ} \mathrm{C}$ to 50 ${ }^{\circ} \mathrm{C}$. Thus, not only materials which are used in the packaging of LEDs plays critical role, but also optimum, thermal management plays against the thermal resistance. At the system level convection to

※ 본 연구는 한국연구재단 논문연구과제 (MSIP) (No.2013-067321) 지원 및 한국대학교 논문연구소 관리로 수행되었습니다.

※ 본 연구는 한국연구재단 논문연구과제 (MEST) (No.2012R1A1A2004366) 지원 및 한국대학교 논문연구소 관리로 수행되었습니다.

- First Author : 광운대학교 전자공학과 RFIC 연구실, zoya2005@naver.com, 학생회원

- Corresponding Author : 광운대학교 전자공학과 RFIC 연구실, nykim@kw.ac.kr, 종신회원

논문번호: KICS2013-05-227, Received May 31, 2013; Reviewed July 31, 2013; Accepted February 18, 2014 
the surrounding environment is the primary method for thermal dissipation and can occur through either natural or forced convection ${ }^{[5]}$. There are three major parameters that impact the junction temperature of the LEDs which are the input power, and thermal resistance between the die and thermal pad, and the ambient temperature. There are many packaging method to eliminate thermal elevation, and reducing size of that of packaging. Most commercially available packaging is chip-on-board (COB) surface provides efficient heat dissipation with compact size. However the thermal design process utilizing COB architectures on power electronic substrates relies heavily on the use of finite element analysis which require time consuming calculation when exploring the parametric design space. This is necessary due to the lack of analytical models which can account for the complex nature of the heat flow through a multilayer power electronic substrate and through the heat sink to the ambient temperature. In this study Si-based LED multi-chip module implementing $\mathrm{COB}$ packaging method were designed from actual fabrication flow process with appropriate parameter values and analyzed by finite element analysis (FEA) using Solidworks 2013 software.

\section{Heat Generation and Transfer in LEDs}

LEDs generate light and heat by using different mechanisms as compared to the incandescent bulb. With the injection of electrical energy, the electron energy will be partly converted into light and partly into heat. Obviously the research into LED technology is focused on optimizing the light emitting efficiency. Currently, the LEDs in the market have an efficiency of about 10\%-20\%. Consequently $80 \%-90 \%$ of the energy is converted into heat. Hence, the challenge of thermal management is to conduct heat from the LED package to the environment with a sufficient heat transfer rate ${ }^{[6]}$.

In general, generated heat from LED chips can be eliminated by conduction, convection and radiation heat transfer mechanisms. The heat is generated by

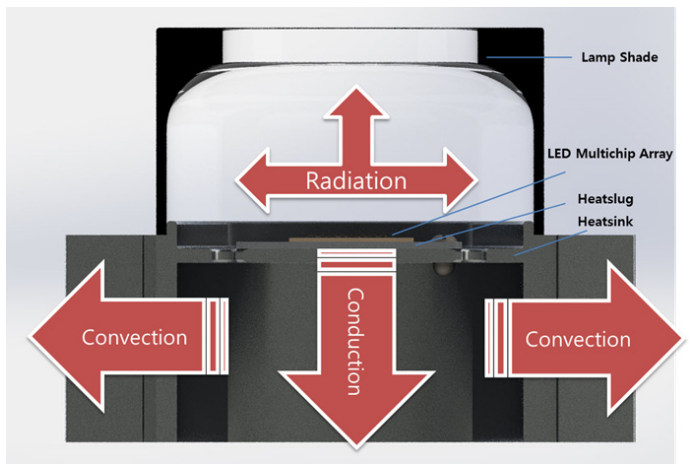

Fig. 1. Heat transfer 3 mode of LED

the LED chip inside the package. Although some of the heat can be dissipated radiation and natural convection along package surface of the multichip array. Normally, $70-80 \%$ of heat is transferred by conduction into heatsink. The transferred heat is dissipated through the heatsink to the surroundings (ambient) by natural convection or radiation. The heatsink could also replaced by other thermal solution which include forced convection or forced air cooling, heat pipe, thermoelectric, synthetic jet flow cooling, liquid system, etc. Compared to forced or active thermal management, natural or passive solution have the advantages of a simple structure, easy fabrication, application flexibility and low cost. Thus, only passive cooling solution will be discussed in this study.

\section{Finite Element Modelling}

In this paper, the structure of Si-based LED multichip array is designed and analyzed shown in Fig. 2. The main structure composed of five parts which are heatsink, heatslug, screw, multichip array, and glass lamp shade. Screw and glass are disabled to save calculation time to for the simulation. Critical parameters and dimensions of the vertical structure of the proposed multichip array are shown in Fig.3. Because conductive layers are thinner than Si substrate, we only consider thermal effect on the $\mathrm{Si}$ substrate to reduce calculation time. The designed chip has an actual size of 610 by $610 \mu \mathrm{m}$, and a thickness is $150 \mu \mathrm{m}$, and it is provided courtesy of Epistar Corporation (model: ES-CADBV24B). The 


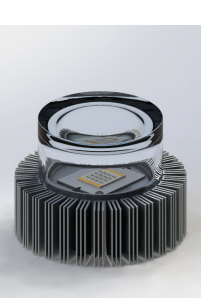

(a)

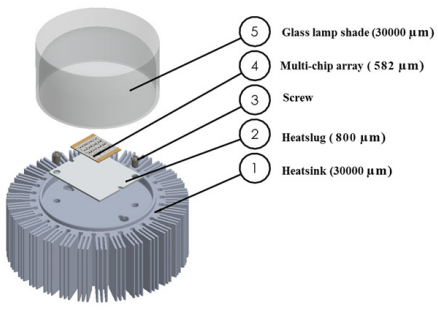

(b)
Fig. 2. (a) Full 3D view of CAD model of Si-based LED module, (b) Exploded view of the proposed Si-based LED module

heatslug provides a thermal path between the multi-chip array and heatsink. The effective area of the multi-chip array is $14540 \mu \mathrm{m}$ by $17970 \mu \mathrm{m}$, and the area divided into 16 paddles ( 4 by 4 ); in each individual paddles contain two chips. The single paddle size is $2800 \mu \mathrm{m}$ by $2800 \mu \mathrm{m}$. The distance between two chips in a single paddle is $535 \mu \mathrm{m}$. The distance between two chips to the adjacent paddle is $1162 \mu \mathrm{m}$. The proposed Si-based multi-chip array is mounted directly on the heatslug. The heatslug consists of two screw-holes and uses the support of screw to keep the heatslug closer to the heatsink, which improves the thermal conduction between the heatsink and heatslug. The total size of the heatslug is $27600 \mu \mathrm{m}$ by $32600 \mu \mathrm{m}$. The screw-hole diameter is $3400 \mu \mathrm{m}$, and the thickness of the heatslug is $800 \mu \mathrm{m}$. Lastly, a glass lamp shade is designed to protect the structure from dust and improve the quality of the light output. Heatsinks are typically manufactured using a variety of metal-forming approaches, including extrusion, stamping, casting, milling, and bending. The extrusion heatsink with rounded fin is generally

\begin{tabular}{|c|c|c|c|}
\hline Component & Material & Thickness $(\mu \mathrm{m})$ & $\begin{array}{c}\text { Thermal } \\
\text { Conductivity } \\
(\mathbf{W} / \mathbf{m} \cdot \mathbf{K})\end{array}$ \\
\hline Chip & Gallium Nitride (GaN) & 150 & 1242.6 \\
\hline \multirow{3}{*}{ Reflective layers } & Silver $(\mathrm{Ag})$ & 3 & 428.7 \\
\hline & Gold $(\mathrm{Au})$ & 1 & 317.6 \\
\hline & Nickel (Ni) & 1 & 91.21 \\
\hline \multirow{3}{*}{ Substrate } & Gold $(\mathrm{Au})$ & 0.5 & 317.6 \\
\hline & Nickel (Ni) & 2 & 91.2 \\
\hline & Copper $(\mathrm{Cu})$ & 7.5 & 386.3 \\
\hline \multirow{3}{*}{$\begin{array}{l}\text { Heat Conductive } \\
\text { Layer }\end{array}$} & Silicon Dioxide ( $\mathrm{SiO} 2$ ) & 1.1 & 10 \\
\hline & Aluminum Oxide (A12O3) & 1.2 & 214.8 \\
\hline & Pure Silicon (Si) & 580 & 151.1 \\
\hline Heatslug & Alloy 1060 & 1000 & 200 \\
\hline Heatsink & Alloy 6061 & 30000 & 170 \\
\hline
\end{tabular}

Fig. 3. Material properties of actual $\operatorname{LEDs}^{[7]}$ implemented in natural convection for LED applications. The outer diameter of the heatsink is $53000 \mu \mathrm{m}$, and the innermost diameter is $50000 \mu \mathrm{m}$. The length of the fin is $15000 \mu \mathrm{m}$, and the height is $30000 \mu \mathrm{m}$. The thickness of the centre base metal is $2000 \mu \mathrm{m}$.

\section{Result and Discussion}

The primary goal of the design was to calculate individual die power of $0.2 \mathrm{~W}$, and examine whether our heatsink with a fin number of 90 and thickness of $30 \mathrm{~mm}$ can effectively dissipate generated heat into the ambient. In general, most LED suppliers suggest that luminaries be designed so that LED junction temperatures are maintained well below 100 ${ }^{\circ} \mathrm{C}$ in typical applications. To optimize the heatsink with this design, the simulated result is determined to be $51.5{ }^{\circ} \mathrm{C}$. Typically, designers use automatic mesh generation. For the results to be accurate, the number of cell size should be high; ultimately, users will require a computer with a large memory. There are 3 different types of cells, solid, fluid and partial, and 2 different types of initial conditions, basic initial and local initial, that are performed to calculate results. We used a method for reducing the number of cell size in the basic initial condition and increasing the number of cell size in the local initial condition. When only accurate result was needed, we used the local initial condition, which included the heatsink, heatslug, and LED multi-chip array, while reducing the overall fluid cell size in the basic initial condition resulting in more accurate results and a ten-fold reduction in time consumption. The number of mesh cells is approximately 800,000, including the solid cell, partial cell, and fluid cell. The optimal thickness of the heatsink and the number of fins were considered, fin numbers of 30 , 60, 90, and 120 fins were examined. Corresponding simulation results are shown in Figs. 4 (a), (b), (c), and (d), where the temperature distribution of the junction, Si-substrate, heatslug, and heatsink are displayed. Heatsinks provide increased surface area to dissipate heat effectively from the LED to the external environment. Key heatsink performance 

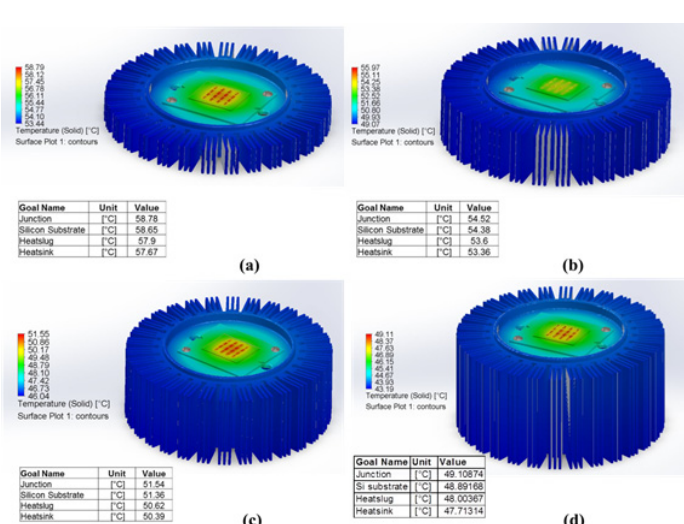

(c)

Fig. 4. Varying thickness of aluminium heatsink at supplied power $6.4 \mathrm{~W}$ (a) $10 \mathrm{~mm}$; (b) $20 \mathrm{~mm}$; (c) $30 \mathrm{~mm}$; (d) $40 \mathrm{~mm}$

parameters include a large surface area to spread the heat generated by the LED and provide access to circulating air, a flat contact area to provide effective heat transfer from the substrate, effective aerodynamic design to ensure effective air circulation, effective thermal transfer within the heatsink, and a secure method of mounting the heatsink to the substrate, which is also required to provide heat transfer from the substrate. Based on simulation, it is determined that when the number of fins is 60 , optimum result of $48.41{ }^{\circ} \mathrm{C}$ is attained, and compared with IR camera measurement results shown in Fig. 6. That is because of adequate space for air circulation from the surface to the external environment. An increase in fin number of the heatsink causes increase in cost and weight. In reality, the heatsink and multi-chip array surface will typically have minor surface imperfections, which impede effective thermal transfer because the surface of the two materials are partially separated by air pockets. To address these deficiencies, properly designed LED thermal management systems use various types of thermal interface materials. To reduce calculation time effectively, the TIM was ignored in this design. As the thickness of the material increases, the temperature gradient increases, which indicates that a high rate of heat transfer will occur. In addition, material conductivity has significant effect on the heat transfer rate. Fig. 5 shows heatsink with varying thicknesses: (a) 10
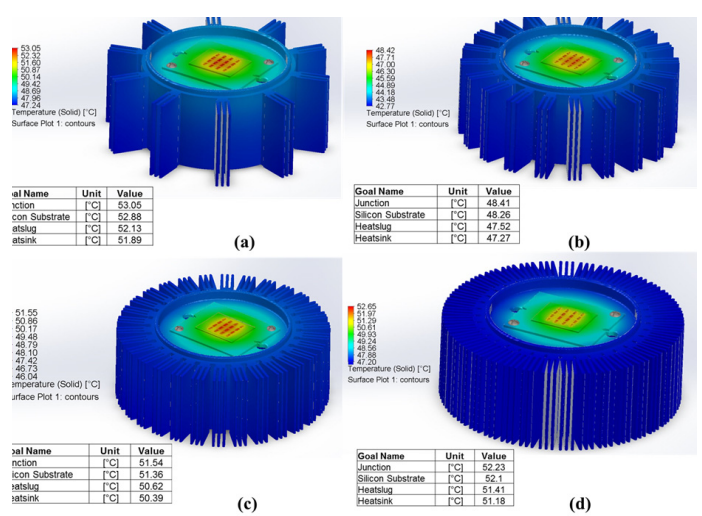

Fig. 5. Varying number of fins for aluminium heatsink at supplied power $6.4 \mathrm{~W}$ (a) 30; (b) 60; (c) 90; (d) 120

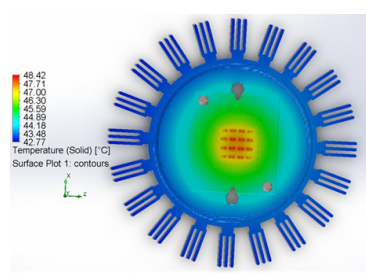

(a)

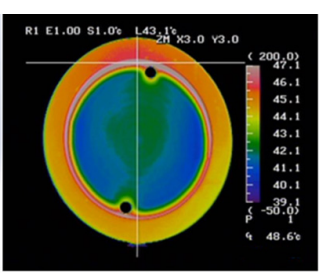

(b)
Fig. 6. Temperature distribution supplied power $6.4 \mathrm{~W}$ (a) simulation results by Solidworks; (b) measurement results by IR camera

$\mathrm{mm}$; (b) $20 \mathrm{~mm}$; (c) $30 \mathrm{~mm}$; and (d) $40 \mathrm{~mm}$ when the number of fins to be 90 . When the thickness was $40 \mathrm{~mm}$, the junction temperature was $49.1^{\circ} \mathrm{C}$. The junction temperature can be controlled and lowered even if the thickness is increased. As the thickness increases, it directly affects to the cost and weight; therefore, luminaire designers need to consider adequate size and heat dissipation.

\section{Conclusion}

In this paper, 6. W Si-based LED packaged module was introduced, simulated and analysed successfully, which has a high thermal conductivity and a low thermal resistance and the thermal stress compared to a metal core printed circuit board (MCPCB). The heatsink analysis is performed by changing the thickness of the heatsink from $10 \mathrm{~mm}$ to $40 \mathrm{~mm}$ and the number of fins from 30 to 120 . The optimum junction temperature is $48.41{ }^{\circ} \mathrm{C}$ and 
the temperature of the packaged actual module is measured by the IR thermal camera to be $48.6{ }^{\circ} \mathrm{C}$. The junction to ambient resistance was based on analytical thermal resistance network and was determined by the optimal condition.

\section{References}

[1] W-H. Chi, T-L. Chou, Ch-N. Han, S-Y. Yang, and K-N. Chiang "Analysis of thermal and luminous performance of MR-16 lighting module," IEEE Trans. Comp. Packag. Technol., vol. 33, no. 4 pp. 716-721, Dec. 2010.

[2] J-H. Choi and M-W. Shin, "Thermal investigation of lighting module" Microelectron Reliab, vol. 52, pp. 830-835, 2012.

[3] H. Fengze, Y. Daoguo, and Z. Guoqi, "Thermal analysis of LED lighting system with different fin heat sinks," $J$. semiconductors, vol. 32, no. 1, Jan. 2011.

[4] A. Christensen and S. Graham, "Thermal effects in packaging high power light emitting diode arrays" Appl. Therm. Eng., vol. 29, pp. 364-371, 2009.

[5] Y. Huaiyu, S. Koh, H-V. Zeijl, A. W. J. Gielen, and Z. Guoqi, "A review of passive thermal management of LED module," $J$. semiconductors, vol. 32, no. 1, Jan. 2011.

[6] C. Wang, W.-S. Lee, F. Zhang, and N.-Y. Kim, "Si-based packaging platform for LED module using electroplating method," Elect. Lett., vol. 46, no. 17, pp. 1220-1221, Aug. 2010.

[7] S. K. Oh and E. B. Goldsmith, "The better manuscript preparation for speedy publication," J. Commun. Networks (JCN), vol. 13, no. 6, pp. 10-16, Dec. 2011.

\section{Zorigt Chuluunbaatar

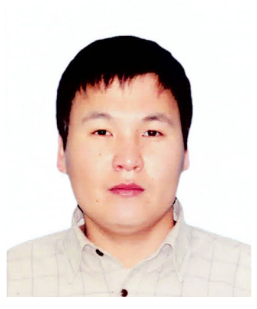 \\ $\mathrm{He}$ received the B.S. degree in electronic engineering from Huree University of Information Science and Technology, Ulaanbaatar, Mongolia, in 2007. He received M.S. degree from Kwangwoon University, South} Korea, in 2012. where he has been working toward the Ph.D. degree in LED package and RFIC passive circuit design. His major research interests include the thermal and optical design of LED packaging and application.

\section{Nam-Young Kim}

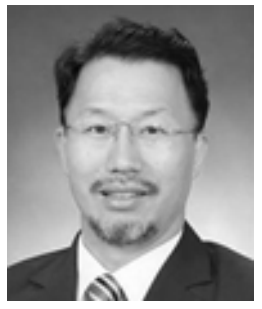

He has received two Masters and two Ph.D. degrees from State University of New York at Buffalo and Midwest University: the M.S. and the Ph.D. in Electronic Engineering. The other degree is M.Div and

D.C.E in Theology. He was a research scientist for CEEM at SUNY at Buffalo in 1994. After completing his research at CEEM at SUNY at Buffalo, he joined the Department of Electronic Engineering of Kwangwoon University as an assistant professor in 1994. His main research focus is in RFIC devices, ICs and systems, which use wireless application techniques in order to develop high speed structures in $\mathrm{GaAs}, \mathrm{Si}$, and other materials. The founder of the RFIC Center, Dr. Kim also serves as director for the Fusion Technology Center of RF and Bio related research. His RFIC research center was honored and sponsored as a ITRC (Information Technology Research Center) by the Ministry of Communication and Information (MIC) of Korea, where he has been acting Director of the RFIC since 2000. He leads the RFIC and RF related Fusion Group at Kwangwoon University, where he has researched along with 12 professors. His research fields are in the areas of RF semiconductor device, RFICs and MMICs, and LED applications. 